\title{
Supportive-Affective Group Experience for Persons with Life-Threatening Illness: Reducing Spiritual, Psychological, and Death-Related Distress in Dying Patients
}

\author{
DOUGLAS K. MILLER, M.D., ${ }^{1}$ JOHN T. CHIBNALL, Ph.D., ${ }^{2}$ SUSAN D. VIDEEN, Ph.D., ${ }^{3}$ \\ and PAUL N. DUCKRO, Ph.D. ${ }^{4}$
}

\begin{abstract}
Background: Attention to psycho-socio-spiritual needs is considered critical by patients with life-threatening illnesses and their caregivers. Palliative care interventions that address these needs-particularly spirituality-are lacking.

Objective: To evaluate the effects of an innovative program to address psycho-socio-spiritual needs in patients with life-threatening illnesses.

Design: A group intervention entitled Life-Threatening Illness Supportive-Affective Group Experience (LTI-SAGE) was developed for reducing patient spiritual, emotional, and deathrelated distress.

Setting/subjects: African American and Caucasian patients $(n=69)$ from two hospitals in St. Louis, Missouri, with life-threatening medical conditions (cancer; human immunodeficiency virus/acquired immune deficiency syndrome [HIV/AIDS]; geriatric frailty; liver, kidney, pulmonary, or cardiovascular disease) were randomly assigned to intervention or control groups. Intervention patients participated in a maximum of 12 LTI-SAGE groups over a 12-month period. Control patients received standard care.

Measurements: Outcome measures were depression symptoms, anxiety, spiritual well-being, and death-related emotional distress.

Results: After attrition, $51(73.9 \%)$ patients completed the trial. At the end of the trial, after factoring in compliance, intervention patients had significantly fewer depression symptoms and death-related feelings of meaninglessness and significantly better spiritual well-being than did control patients.

Conclusions: The use of the LTI-SAGE model for enhancing the end-of-life illness experience is promising.

\section{INTRODUCTION}

T HERE IS GENERAL AGREEMENT that care for patients at the end of life is lacking in several regards. Despite Elisabeth Kübler-Ross's germi-

nal publications-more than 25 years ago-on patients' needs at end of life, ${ }^{1,2}$ the psycho-sociospiritual needs of dying patients remain marginalized. ${ }^{3,4}$ Despite numerous articles and legal cases clarifying and emphasizing the moral, eth-

\footnotetext{
${ }^{1}$ Indiana University Center for Aging Research, Regenstrief Institute, Inc., Indianapolis, Indiana.

${ }^{2}$ Department of Psychiatry, Saint Louis University School of Medicine, St. Louis, Missouri.

${ }^{3}$ Pastoral Care, Saint Louis University Health Sciences Center, St. Louis, Missouri.

${ }^{4}$ Department of Community and Family Medicine, Saint Louis University School of Medicine, St. Louis, Missouri.
} 
ical, and legal issues surrounding end-of-life decision making, end-of-life practices remain disconnected, inappropriate, and ineffective in relieving patient and family distress. 5,6 Even expensive, large-scale interventions to improve end-of-life care of critically ill hospitalized patients have met with little success for changing the state of affairs at end-of-life. ${ }^{7}$

One of the most critical aspects of managing life-threatening illnesses that eludes modern medicine is the desire among patients to be helped to "live well until they die"; to prepare for death psychologically, emotionally, and spiritually; to successfully address issues related to their important personal relationships that have been raised by the illness and the threat of death; and to focus on quality of life and well-being in their waning days rather than medically-intense interventions. ${ }^{3,8-10}$ Regarding end-of-life wishes, Brody and colleagues ${ }^{10}$ have described this effort as a switch from "tactics" (centered on biomedical interventions) to "strategies" (centered on patient-derived end-of-life goals). As a response to this focus on living well and psycho-socio-spiritual well-being in the face of death, psychotherapeutic support groups have been developed. The most comprehensive and successful of these has been that of Spiegel and colleagues ${ }^{11}$ regarding supportive-expressive group therapy for women with recurrent breast cancer. This and other forms of group therapy have been shown to have significant effects on mood, depression, pain-related suffering, maladaptive coping, and fatigue among patients with cancer. ${ }^{11,12}$

In line with this effort toward improving through psychosocial interventions-quality of life and well-being among persons with lifethreatening illness, we developed a group intervention that incorporated the only component of the psycho-socio-spiritual framework ${ }^{3}$ that has not been systematically studied in group interventions for end-of-life: spirituality. Certainly, attention to spiritual and religious aspects of the illness experience is a burgeoning and high profile area for current research. 8,13 Our intervention was designed as a group sharing and learning experience that focused on the spiritual, emotional/psychological, and relational aspects of living well while dying. These aspects of the life-threatening illness experience are consistent with Ellison's conceptualization of basic human needs-including intimacy and a sense of belonging (need for relating), satisfaction with one- self (need for emotional stability and sense of self), and life purpose/meaning (the need for transcendence or "spirituality") ${ }^{14}$ —and with the needs considered most important by dying patients and the most neglected in the medical treatment of patients with life-threatening illnesses. ${ }^{3}$ The intervention was not designed to be formal group psychotherapy, nor to espouse or support one particular religion or spiritual approach. It was designed to reduce psychological, spiritual, and death-related distress in patients with life-threatening illnesses by acknowledging the central role of spiritual (i.e., existential, transcendent) processes in the progression toward death and the relationship of these processes to despondency and coping. ${ }^{15}$ Given that research has documented the significant negative psychological and behavioral effects of depression, anxiety, spiritual distress, and death-related suffering in these patients, ${ }^{11,12,16}$ the intervention was designed to reduce these negative outcomes by offering strategies for living well despite lifethreatening illness. The intervention was delivered within a community of supporters and emphasized the psych-socio-spiritual aspects of living and dying. The intervention is known as the Supportive-Affective Group Experience for Persons with Life-Threatening Illness (LTISAGE). This paper reports on a preliminary, 12month, randomized pretest-posttest trial to evaluate its efficacy. Specifically, it was hypothesized that participants in the LTI-SAGE would have, after 1 year, significantly less depression, anxiety, and death-related psychological distress and significantly better spiritual well-being than participants in the control group.

\section{METHODS}

\section{Participants and recruitment}

The institutional review boards of Saint Louis University and Forest Park Hospital (both in St. Louis, Missouri) approved the study. Ambulatory patients were then recruited from outpatient services of the internal medicine department at Saint Louis University Health Sciences Center and a private oncology service at Forest Park Hospital. Eligible patients were those with serious medical conditions that would probably not cause their death in 6 months but that were severe enough to create a limited life expectancy and therefore to warrant a consideration of end- 
of-life issues (as determined by their primary physicians). Diagnostic categories included cancer, liver disease, pulmonary disease, kidney disease, cardiac disease, human immunodeficiency virus/acquired immune deficiency syndrome (HIV/AIDS), and geriatric frailty. The last category was defined as advanced age combined with a high morbidity burden, but without a dominant life-threatening disease. Recruitment strategies included letters to patients (from their primary physicians); on-site, face-to-face recruitment at the clinics; and referrals from primary physicians. ${ }^{17}$ Patients were informed that the study would require a 12-month commitment and that they had a 50:50 chance of being assigned to the intervention group (monthly, 75-minute supportive-affective groups) or the control group. Patients were told that they would be reimbursed for travel, parking, and for time spent in completing the outcome assessment (\$35). In addition, all patients were told that they would receive tote bags, coffee cups, and workbooks as part of their participation. Approximately $30 \%$ of all the patients approached by one or more recruitment methods agreed to participate, and a convenience sample of 98 patients was obtained through these mechanisms. Reasons for not entering the study were primarily health-related (i.e., the patient felt that he/she was too ill to commit to a 1-year program). Following informed consent, patients completed the baseline materials and were randomly assigned to either the intervention group or the control group.

\section{Materials}

At baseline and posttest (12 months), patients completed the outcome measures for the study, which included the Beck Depression Inventory (BDI: 21 items, 0-3 scale, 0-63 score range), the Spielberger State Anxiety Inventory (SSAI: 20 items, 1-4 scale, 20-80 score range), the Spiritual Well-Being Scale (SWS: two subscores, each 10 items, 1-6 scale, 6-60 score range), and the Death Distress Scale (DDS: 11 items, 0-1 scale, 0-11 score range). The BDI and SSAI are standard assessment instruments, where higher scores indicate more depression symptoms and anxiety, respectively. ${ }^{18,19}$ Internal consistency reliability in this study was 0.92 for the BDI and 0.96 for the SSAI. The SWS measures spiritual well-being on a "vertical" dimension (religious spiritual wellbeing in relation to a higher power or God, SWS-
RG) and on a "horizontal" dimension (existential spiritual well-being in relation to life purpose and meaning, SWS-EX), where higher scores indicate greater spiritual well-being. ${ }^{20}$ Internal consistency was 0.86 for SWS-RG and 0.89 for SWS-EX. The DDS was designed to measure a combination of death-related depression (items taken from the Death Depression Scale) and anxiety (items taken from the Death Anxiety Scale), with higher scores indicating more distress. ${ }^{21,22}$ We modified the original 10-item DDS scale slightly by removing an inappropriate item for our study population (fear of getting cancer) and, consistent with the factor structure of the DDS, ${ }^{21}$ added two more items from the Death Depression Scale ("I fear dying a painful death" and "I get depressed when I think about death"), for a total of 11 items. Although the internal consistency of this scale was high, at 0.83 , it was nevertheless factor analyzed to determine if multiple constructs were being measured in this sample of medically ill participants (see Results section).

Other standardized measures included the Illness Disability Index (IDI: 7 items, 0-10 scale, 0-70 score range) and the Perceived Social Support Inventory (PSSI: 40 items, 0-1 scale, 0-40 score range). ${ }^{23,24}$ The IDI is an adaptation of the Pain Disability Index and measures illness-related disability, with higher scores indicating more disability (i.e., illness-related interference with role functioning regarding home, social life, occupation, self-care, etc.), and had an internal consistency of 0.90 . The PSSI measures amount of social support received from family and friends, with higher scores indicating more support, and had an internal consistency of 0.95. These measures were not expected to change in response to the intervention. Other data collected included patient age, gender, race, living arrangements (lives with others versus lives alone; considered a form of social support), religious denomination, and medical diagnoses.

\section{Intervention}

Patients assigned to the control group were sent quarterly mailings of existing, readily available self-help resource materials. The program coordinator also called them at least once every three months to verify that they were receiving the mailings. During these calls, the coordinator avoided any assistance with processing any emotional, relational, or spiritual issues. 
Patients in the intervention group met monthly for 12 months, for 75 minutes per session, in groups of 3-8 patients and 1-2 group facilitators. One patient informal caregiver (e.g., spouse, friend) was also invited to attend the group sessions with the patient. However, only approximately $20 \%$ of patients brought caregivers to the groups on a regular basis. Groups were constituted based on diagnosis and race. There was one group of African American frailty patients (African American facilitator); one group of Caucasian frailty patients (Caucasian facilitator); one group of African American patients with cancer or organ-based diseases (African American facilitator); one group of Caucasian patients with cancer or organ-based diseases (Caucasian facilitator); and one mixed-race group of HIV/AIDS patients (African American facilitator).

Groups were racially constituted because of concerns on the part of African Americans in the pilot/pretesting phase of the project that predominantly Caucasian groups would not serve the needs of racial minorities. This concern is supported in the literature, which indicates that African Americans in majority Caucasian support, therapy, or discussion groups report less satisfaction and success from the experience and perceive less cooperation and attention to their voices and issues than in racially homogeneous groups or African American majority groups. ${ }^{25,26}$ Postproject evaluations indicated that the African American patients appreciated the racially homogeneous groups and African American facilitators and felt that their experience would have been less beneficial and meaningful had they had to be conscious of race issues during the group meetings. On the other hand, the HIV/AIDS group was racially mixed because of small numbers of patients, the group's relative youth, and the strong discriminatory effect of the disease that moderated the race effect.

The group process was defined as "adult affective education and support," not therapy. The underlying purpose of LTI-SAGE was for each group member to develop a greater sense of hope, courage, and connection. The process relied heavily on discussing experiences, expressing feelings, and sharing support. Because the goal was to promote well-being, the sequence of topics was meant to be flexibly applied, as the needs of the group dictated (e.g., the suggested flow of topics might be interrupted upon the death of a group member). Early topics were meant to be less emo- tionally threatening so that the group could develop trust. Later topics were designed to address the more immediate, emotional, and spiritually challenging aspects of life-threatening illness. In sequence, the 12 sessions addressed: group dynamics and expectations; recognizing and asserting needs; feelings and emotions; symptom control; living well while ill; intimate relationships; spiritual needs; asking for help; end-of-life care planning/decision making; legacy; hope and gratitude; and group closure. Each group focused on the psycho-socio-spiritual aspects of the topic for that session. The group process format encouraged immediate, affective, personal, specific, empathic, active, and spiritual discussions, feedback, and interactions. The most important aspect of the group dynamic was "process is more important than content." The curriculum was considered a vehicle for carrying the group members to a sense of connection to others, themselves, and the transcendent. In light of this process format, group facilitators were not psychotherapists but were trained to be mediators, mobilizers, and enablers. Facilitators were made aware of the limitations of their role and were taught to recognize serious crises that required professional mental health services. The facilitator role (and training) regarding group process was purposefully inclined toward (1) living in the present moment, (2) sharing authentically, (3) finding meaning by facing death and life together, and (4) coming to see personal value having meaning beyond illness and death. Facilitators focused on listening, endorsing, and supporting personal reflections from participants, and reflecting the themes as they emerged from the group discussions. To facilitate this supportive, personally reflective environment, probing questions or confrontational questions were firmly curtailed by the facilitators. Between sessions, patients were encouraged to continue their processing of the issues addressed during the group meetings. The program coordinator also made at least one telephone call between sessions to each patient in the intervention group. The project's operations manual explicates full details of the program, the role of the group facilitator, and group process goals. ${ }^{27}$

\section{Data analysis strategy}

Differences in posttest scores between the intervention and control groups were evaluated using analysis of covariance. For all outcome 
variables, posttest differences were adjusted for baseline scores on the outcome variable being tested. In addition, adjustments were made, where appropriate, for religious denomination, illness-related disability, and social support. Because of the small size of the sample that completed the study (see Results), the critical alpha level for statistical significance was set at $p<$ 0.10 . While this increased the power of the analyses, it also increased the probability of a false-positive finding.

\section{RESULTS}

\section{Factor analysis of death distress scale}

To investigate whether death distress was multifactorial in this sample, the death distress items were submitted to a principal components analysis. The analysis yielded four factors that explained $72.1 \%$ of the variance in the original items. This indicated that death distress was not a unitary concept in this sample. Factor 1 (23.8\% of the variance) was labeled death meaninglessness (D-MNG) and included four items (with factor loadings in parentheses): death is the ultimate failure of life (0.94); death deprives life of meaning (0.79); death does not rob life of meaning (reverse-scored) (0.73); I get depressed when I think about death (0.61). Internal consistency for these items was 0.82 . Factor 2 (17.0\% of the variance) was labeled death fear (D-FER) and included two items: I feel that the future holds nothing for me to fear (reverse-scored) (0.79); I am not at all afraid to die (reverse-scored) (0.74). Internal consistency for this factor was 0.54 . Factor $3(15.8 \%$ of the variance) was labeled death reactivity (D-REA) and included two items: I am terribly upset by the shortness of life (0.83); When I think of death, I feel tired and lifeless (0.76). Internal consistency for this factor was 0.57 . Factor 4 (15.5\% of the variance) was labeled death apprehension (D-APP) and included three items: I dread to think of the death of friends and loved ones (0.85); The thought of death never bothers me (reverse scored) (0.72); I fear dying a painful death (0.57). Internal consistency for this factor was 0.63 . These four subscales were used to represent death factors in the current study, although the internal consistency of the last three subscales was marginal, in part attributable to the small number of items.
Retention and sample description

Ninety-eight patients were recruited to participate in the trial. Of this number, 69 (70.4\%) completed the baseline evaluation and 29 (29.6\%) elected not to participate prior to completion of the baseline materials and randomization. Of the 29 patients who dropped out prior to baseline, $51.7 \%(n=15)$ were Caucasian and $48.3 \%(n=$ 14) were African American. Of the 69 patients who completed the baseline assessment, $63.8 \%$ $(n=44)$ were Caucasian and $36.2 \%(n=25)$ were African American. This difference in retention as a function of race was not statistically significant, $\chi^{2}(1)=0.8, p=0.34$.

Of the 69 patients retained in the trial, 37 $(53.6 \%)$ were randomly assigned to the intervention group and $32(46.4 \%)$ were randomly assigned to the control group. Of those randomized, $51(73.9 \%)$ remained in the trial and completed the posttest assessments (28 in the intervention group, $75.7 \%$ versus 23 in the control group, $\left.71.9 \%, \chi^{2}(1)=0.01, p=0.93\right)$. Of the 18 patients who did not complete the trial, 5 died (1 in the intervention group, 4 in the control group), and 13 elected to end their participation due to declining health or related issues (8 in the intervention group, 5 in the control group). Table 1 compares the baseline data for the completers and dropouts. There were significantly more women in the drop out group than in the completer group.

Although 51 patients completed the posttest assessments, a subset of intervention patients $(n=7)$ was noncompliant with the treatment. This group of seven attended, on average, only 3 of the 12 group meetings (standard deviation $[S D]=1.5$; range, $1-5)$, while the remaining 21 intervention patients attended, on average, 9 of the 12 groups $(\mathrm{SD}=0.9$; range, $8-12), t(26)=$ 12.4, $p<0.001, \eta^{2}=0.86$. As reported during debriefing with the group facilitators, when session-noncompliant patients attended groups they tended to be somewhat less involved in group activities than the compliant patients. In light of this situation, all analyses were done in two ways: on an intent-to-treat basis ( $n=51$, including the 7 noncompliant patients) and with the 7 noncompliant patients removed from the intervention group $(n=44)$. Compared to the 21 compliant intervention patients, the 7 noncompliant patients were much younger (mean age $=$ $45.1, \mathrm{SD}=12.6$, versus compliant mean age $=$ 
Table 1. Baseline Characteristics of Trial Completers and Drop-Outs

\begin{tabular}{|c|c|c|c|c|}
\hline & \multicolumn{2}{|c|}{$\%(\mathrm{n})$ or $\mathrm{M}(\mathrm{SD})$} & \multirow[b]{2}{*}{ Statistic } & \multirow[b]{2}{*}{$\mathrm{p}$} \\
\hline & $\begin{array}{c}\text { Completers } \\
(\mathrm{n}=51)\end{array}$ & $\begin{array}{l}\text { Drop-outs } \\
(\mathrm{n}=18)\end{array}$ & & \\
\hline \multicolumn{5}{|l|}{ Group } \\
\hline Intervention & $54.9 \%(28)$ & $50.0 \%(9)$ & \multirow[t]{2}{*}{$\chi^{2}(1)=0.0$} & \multirow[t]{2}{*}{0.93} \\
\hline Control & $45.1 \%(23)$ & $50.0 \%(9)$ & & \\
\hline \multicolumn{5}{|l|}{ Race } \\
\hline African American & $31.4 \%(16)$ & $50.0 \%(9)$ & \multirow{2}{*}{$\chi^{2}(1)=1.3$} & \multirow[t]{2}{*}{0.26} \\
\hline Caucasian & $68.6 \%(35)$ & $50.0 \%(9)$ & & \\
\hline \multicolumn{5}{|l|}{ Gender } \\
\hline Male & $43.1 \%(22)$ & $16.7 \%(3)$ & \multirow{2}{*}{$\chi^{2}(1)=3.0$} & \multirow{2}{*}{0.08} \\
\hline Female & $56.9 \%(29)$ & $83.3 \%(15)$ & & \\
\hline \multicolumn{5}{|l|}{ Living arrangements } \\
\hline Lives alone & $35.3 \%(18)$ & $33.3 \%(6)$ & \multirow[t]{2}{*}{$\chi^{2}(1)=0.0$} & \multirow[t]{2}{*}{0.99} \\
\hline Lives with others & $64.7 \%(33)$ & $66.7 \%(12)$ & & \\
\hline \multicolumn{5}{|l|}{ Diagnosis } \\
\hline Disease & $70.6 \%(36)$ & $55.6 \%(10)$ & \multirow{2}{*}{$\chi^{2}(1)=0.8$} & \multirow[t]{2}{*}{0.38} \\
\hline Frailty & $29.4 \%(15)$ & $44.4 \%(8)$ & & \\
\hline \multicolumn{5}{|l|}{ Religious denomination } \\
\hline Catholic & $37.3 \%(19)$ & $33.3 \%(6)$ & \multirow{3}{*}{$\chi^{2}(2)=0.1$} & \multirow[t]{3}{*}{0.96} \\
\hline Baptist & $25.5 \%(13)$ & $27.8 \%(5)$ & & \\
\hline Other & $37.3 \%(19)$ & $38.9 \%(7)$ & & \\
\hline Age (years) & $61.2(16.8)$ & $59.9(20.8)$ & $t(67)=0.3$ & 0.79 \\
\hline Social support (PSSI) & $22.0(12.2)$ & $26.8(10.8)$ & $t(67)=1.5$ & 0.14 \\
\hline Illness-related disability (IDI) & $28.9(18.3)$ & $26.1(16.4)$ & $t(67)=0.6$ & 0.56 \\
\hline \multicolumn{5}{|l|}{ Psychological factors } \\
\hline Depression symptoms (BDI) & $14.6(10.3)$ & $15.1(12.4)$ & $t(67)=0.1$ & 0.88 \\
\hline State anxiety (SSAI) & $44.1(16.4)$ & $45.9(16.5)$ & $t(67)=0.4$ & 0.69 \\
\hline \multicolumn{5}{|l|}{ Spiritual factors } \\
\hline Religious spiritual well-being (SWS-RG) & $46.9(10.3)$ & $48.4(9.3)$ & $t(67)=0.5$ & 0.59 \\
\hline Existential spiritual well-being (SWS-EX) & $41.5(11.1)$ & $41.8(11.3)$ & $t(67)=0.1$ & 0.92 \\
\hline \multicolumn{5}{|l|}{ Death factors } \\
\hline Meaningless (D-MNG) & $0.84(1.3)$ & $1.1(1.4)$ & $t(67)=0.7$ & 0.46 \\
\hline Fear (D-FER) & $0.82(0.82)$ & $0.94(0.83)$ & $t(67)=0.5$ & 0.61 \\
\hline Reactivity (D-REA) & $0.45(0.70)$ & $0.53(0.72)$ & $t(67)=0.4$ & 0.69 \\
\hline Apprehension (D-APP) & $2.2(1.0)$ & $1.9(1.1)$ & $t(67)=0.9$ & 0.35 \\
\hline
\end{tabular}

BDI, Beck Depression Inventory; PSSI, Perceived Social Support Inventory; SSAI, Spielberger State Anxiety Inventory; IDI, Illness Disability Index.

67.2, $\mathrm{SD}=15.9 ; t(26)=3.3, p<0.01)$ and had more illness-related disability (mean IDI $=37.7$, $\mathrm{SD}=9.2$ versus compliant mean $\mathrm{IDI}=22.7$, $\mathrm{SD}=15.9 ; t(26)=2.3, p<0.05)$. Furthermore, compared to the 21 compliant patients, the 7 noncompliant patients had a significant drop in their religious spiritual well-being between baseline and posttest (mean SWS-RG difference $=-4.7, S D=7.9$, versus compliant mean SWS-RG difference $=4.1, \mathrm{SD}=6.8, t(26)=2.9$, $p<0.01)$. No other differences between these two groups approached significance.

Of the 51 patients who completed the trial, baseline comparisons between the intervention and control groups showed slight differences only on death fear (D-FER), with control patients having lower scores than intervention patients. These data are shown in Table 2.

\section{Outcomes}

Intent-to-Treat Analysis. Table 3 shows the results of the intent-to-treat analyses for the primary outcome variables.

Psychological Factors. Depression symptoms were slightly lower, but not significantly so, at posttest in the intervention group after adjustment for baseline depression, religious denomination, and social support, $F(1,45)=2.5, p=0.12$. State anxiety also showed no significant differential change after adjustment for baseline anx- 
Table 2. Baseline Characteristics of Intervention and Control Groups

\begin{tabular}{|c|c|c|c|c|}
\hline & \multicolumn{2}{|c|}{$\%(\mathrm{n})$ or $\mathrm{M}(\mathrm{SD})$} & \multirow[b]{2}{*}{ Statistic } & \multirow[b]{2}{*}{$\mathrm{p}$} \\
\hline & $\begin{array}{l}\text { Intervention } \\
\quad(\mathrm{n}=28)\end{array}$ & $\begin{array}{l}\text { Control } \\
(\mathrm{n}=23)\end{array}$ & & \\
\hline \multicolumn{5}{|l|}{ Race } \\
\hline African-American & $32.1 \%(9)$ & $30.4 \%(7)$ & \multirow[t]{2}{*}{$\chi^{2}(1)=0.0$} & \multirow[t]{2}{*}{0.99} \\
\hline Caucasian & $67.9 \%(19)$ & $69.6 \%(16)$ & & \\
\hline \multicolumn{5}{|l|}{ Gender } \\
\hline Male & $35.7 \%(10)$ & $52.2 \%(12)$ & \multirow[t]{2}{*}{$\chi^{2}(1)=0.8$} & \multirow[t]{2}{*}{0.37} \\
\hline Female & $64.3 \%(18)$ & $47.8 \%(11)$ & & \\
\hline \multicolumn{5}{|l|}{ Living arrangements } \\
\hline Lives alone & $46.4 \%(13)$ & $21.7 \%(5)$ & \multirow[t]{2}{*}{$\chi^{2}(1)=2.4$} & \multirow[t]{2}{*}{0.12} \\
\hline Lives with others & $53.6 \%(15)$ & $78.3 \%(18)$ & & \\
\hline \multicolumn{5}{|l|}{ Diagnosis } \\
\hline Disease & $71.4 \%(20)$ & $69.6 \%(16)$ & \multirow{2}{*}{$\chi^{2}(1)=0.0$} & \multirow[t]{2}{*}{0.99} \\
\hline Frailty & $28.6 \%(8)$ & $30.4 \%(7)$ & & \\
\hline \multicolumn{5}{|l|}{ Religious denomination } \\
\hline Catholic & $35.7 \%(10)$ & $39.1 \%(9)$ & \multirow{3}{*}{$\chi^{2}(2)=0.3$} & \multirow{3}{*}{0.86} \\
\hline Baptist & $28.6 \%(8)$ & $21.7 \%(5)$ & & \\
\hline Other & $35.7 \%(10)$ & $39.1 \%(9)$ & & \\
\hline Age (years) & $61.7(17.8)$ & 60.7 (15.9) & $t(49)=0.2$ & 0.83 \\
\hline Social support (PSSI) & $21.6(12.0)$ & $22.5(12.7)$ & $t(49)=0.3$ & 0.78 \\
\hline Illness-related disability (IDI) & $26.5(15.8)$ & $32.0(20.8)$ & $t(49)=1.1$ & 0.29 \\
\hline \multicolumn{5}{|l|}{ Psychological factors } \\
\hline Depression symptoms (BDI) & $13.9(10.4)$ & $15.5(10.3)$ & $t(49)=0.6$ & 0.57 \\
\hline State anxiety (SSAI) & $45.9(16.0)$ & $42.0(16.9)$ & $t(49)=0.8$ & 0.40 \\
\hline \multicolumn{5}{|l|}{ Spiritual factors } \\
\hline Religious spiritual well-being (SWS-RG) & $47.9(9.8)$ & $45.6(11.1)$ & $t(49)=0.8$ & 0.43 \\
\hline Existential spiritual well-being (SWS-EX) & $41.3(10.8)$ & $41.7(11.7)$ & $t(49)=0.1$ & 0.90 \\
\hline \multicolumn{5}{|l|}{ Death factors } \\
\hline Meaningless (D-MNG) & $1.1(1.5)$ & $0.52(1.0)$ & $t(49)=1.6$ & 0.12 \\
\hline Fear (D-FER) & $1.0(0.77)$ & $0.61(0.84)$ & $t(49)=1.7$ & 0.09 \\
\hline Reactivity (D-REA) & $0.46(0.69)$ & $0.43(0.73)$ & $t(49)=0.1$ & 0.88 \\
\hline Apprehension (D-APP) & $2.2(1.1)$ & $2.1(1.0)$ & $t(49)=0.2$ & 0.87 \\
\hline
\end{tabular}

BDI, Beck Depression Inventory; PSSI, Perceived Social Support Inventory; IDI, Illness Disability Index; SSAI, Spielberger State Anxiety Inventory.

iety, religious denomination, and social support, $F(1,46)=0.1, p=0.70$.

Spiritual Factors. Religious spiritual well-being did not change significantly after adjustment for baseline religious spiritual well-being, religious denomination, illness-related disability, and social support, $F(1,45)=0.5, p=0.47$. Existential spiritual well-being also did not change significantly after correction for covariates, $F(1,43)=$ $0.0, p=0.91$.

Death Factors. Death meaninglessness (DMNG) was significantly lower at posttest in the intervention group after adjustment for baseline death meaninglessness, religious denomination, illness-related disability, and social support, $F(1,44)=3.0, p=0.09, \eta^{2}=0.07$. None of the other death factors changed significantly, includ- ing with the addition of covariates: D-FER, $F(1,48)=1.7, p=0.20$; D-REA, $F(1,45)=2.2, p=$ 0.14 ; and D-APP, $F(1,43)=0.0, p=0.90$.

Compliant Patients Only. The data were reanalyzed to exclude the 7 noncompliant intervention patients. As shown in Table 4, with the noncompliant patients omitted, the effects for depression $(F(1,38)=4.7, p<0.05)$ and religious spiritual well-being $(F(1,38)=3.9, p=0.054)$ were significant at $p<0.10$. The effect for death meaninglessness remained positive, $F(1,38)=3.3, p<$ 0.09 . No other results were affected by the removal of the 7 noncompliant patients. The difference for SWS-RG is not surprising, given the fact that the 7 noncompliant patients had a change in their religious spiritual well-being score that was the opposite of that for the 21 compliant intervention patients. 
Table 3. Posttest Means for Control and Intervention Groups: Intention-to-Treat Analysis

\begin{tabular}{|c|c|c|c|c|}
\hline & \multicolumn{2}{|c|}{$M(95 \% C I)$} & \multirow[b]{2}{*}{$\mathrm{p}$} & \multirow[b]{2}{*}{$\eta^{2 \mathrm{a}}$} \\
\hline & $\begin{array}{l}\text { Intervention } \\
\quad(\mathrm{n}=28)\end{array}$ & $\begin{array}{l}\text { Control } \\
(\mathrm{n}=23)\end{array}$ & & \\
\hline \multicolumn{5}{|l|}{ Psychological factors } \\
\hline Depression symptoms $(\mathrm{BDI})^{\mathrm{b}}$ & $12.1(10.3-13.9)$ & $14.2(12.2-16.2)$ & 0.12 & 0.05 \\
\hline State anxiety $(\mathrm{SSAI})^{\mathrm{b}}$ & $37.7(34.6-40.8)$ & $38.6(35.2-42.0)$ & 0.70 & 0.00 \\
\hline \multicolumn{5}{|l|}{ Spiritual factors } \\
\hline Religious spiritual well-being (SWS-RG) ${ }^{c}$ & $49.1(46.7-51.5)$ & $47.7(45.0-50.4)$ & 0.47 & 0.01 \\
\hline Existential spiritual well-being (SWS-EX) ${ }^{\mathrm{c}}$ & $43.9(41.5-46.3)$ & $44.1(41.5-46.7)$ & 0.91 & 0.00 \\
\hline \multicolumn{5}{|l|}{ Death factors } \\
\hline Meaninglessness (D-MNG) ${ }^{\mathrm{c}}$ & $0.39(0.13-0.65)$ & $0.75(0.46-1.04)$ & 0.09 & 0.07 \\
\hline Fear $(D-F E R)^{\mathrm{d}}$ & $0.79(0.57-1.01)$ & $0.56(0.31-0.81)$ & 0.20 & 0.03 \\
\hline Reactivity (D-REA) ${ }^{\mathrm{b}}$ & $0.27(0.08-0.46)$ & $0.49(0.28-0.70)$ & 0.14 & 0.05 \\
\hline Apprehension (D-APP) ${ }^{\mathrm{c}}$ & $1.8(1.5-2.1)$ & $1.9(1.6-2.2)$ & 0.90 & 0.00 \\
\hline
\end{tabular}

\section{DISCUSSION}

Seriously ill patients and their caregivers are at least as concerned about spiritual, emotional, and relational issues in their illness experience and preparation for death as they are about medical interventions, and possibly more so. ${ }^{1-3}$ The LTI-SAGE is designed to reduce emotional distress in these patients, improve spiritual wellbeing, and empower patients in their illness ex- perience as they relate to the medical system. In the tradition of Spiegel, Fawzy, and others, $3,11,12$ our intervention addressed the psycho-sociospiritual aspects of life-threatening illness and considerations of life and death. The results of this randomized trial indicated qualified support for the efficacy of LTI-SAGE in reducing depression symptoms, increasing spiritual wellbeing, and reducing death-related feelings of meaninglessness.

Table 4. Posttest Means for Control and Intervention Groups: ExCluding NONCOMPLIANT INTERVENTION PATIENTS

\begin{tabular}{|c|c|c|c|c|}
\hline & \multicolumn{2}{|c|}{$M(95 \% C I)$} & \multirow[b]{2}{*}{$\mathrm{p}$} & \multirow[b]{2}{*}{$\eta^{2 \mathrm{a}}$} \\
\hline & $\begin{array}{l}\text { Intervention } \\
\quad(\mathrm{n}=21)\end{array}$ & $\begin{array}{l}\text { Control } \\
(\mathrm{n}=23)\end{array}$ & & \\
\hline \multicolumn{5}{|l|}{ Psychological factors } \\
\hline Depression symptoms $(\mathrm{BDI})^{\mathrm{b}}$ & $10.9(9.0-12.8)$ & $13.9(12.1-15.7)$ & 0.04 & 0.11 \\
\hline State anxiety $(\mathrm{SSAI})^{\mathrm{b}}$ & $36.3(32.8-39.8)$ & $38.0(34.6-41.4)$ & 0.49 & 0.01 \\
\hline \multicolumn{5}{|l|}{ Spiritual factors } \\
\hline Religious spiritual well-being (SWS-RG) ${ }^{c}$ & $50.5(48.0-53.0)$ & $47.0(44.7-49.3)$ & 0.05 & 0.09 \\
\hline Existential spiritual well-being (SWS-EX) ${ }^{\mathrm{c}}$ & $44.8(42.2-47.4)$ & $44.3(41.8-46.8)$ & 0.79 & 0.00 \\
\hline \multicolumn{5}{|l|}{ Death factors } \\
\hline Meaninglessness (D-MNG) ${ }^{\mathrm{b}}$ & $0.32(0.02-0.62)$ & $0.71(0.43-0.99)$ & 0.08 & 0.08 \\
\hline Fear $(\mathrm{D}-\mathrm{FER})^{\mathrm{d}}$ & $0.78(0.52-1.04)$ & $0.59(0.34-0.84)$ & 0.31 & 0.03 \\
\hline Reactivity (D-REA) ${ }^{\mathrm{b}}$ & $0.31(0.11-0.51)$ & $0.45(0.26-0.64)$ & 0.33 & 0.02 \\
\hline Apprehension (D-APP)c & $1.9(1.6-2.2)$ & $1.8(1.5-2.1)$ & 0.56 & 0.01 \\
\hline
\end{tabular}

${ }^{a} \eta^{2}$ indicates the percentage of variance accounted for in the outcome variable by group designation.

${ }^{b}$ Adjusted for baseline score, religious denomination, and social support.

${ }^{\mathrm{c} A d j u s t e d ~ f o r ~ b a s e l i n e ~ s c o r e, ~ r e l i g i o u s ~ d e n o m i n a t i o n, ~ i l l n e s s-r e l a t e d ~ d i s a b i l i t y, ~ a n d ~ s o c i a l ~ s u p p o r t . ~}$

dAdjusted for baseline score.

BDI, Beck Depression Inventory; SSAI, Spielberger State Anxiety Inventory; CI, confidence interval. 
The distinctive characteristic of our intervention is that it incorporates spirituality into the model of change and experience, within a context of immediate, focused, affective discussion of the nonmedical facets of serious illness, without the necessity of a licensed therapist. With respect to these characteristics, the literature is generally supportive of the positive role of spirituality in coping with serious illness and dying, ${ }^{29,30}$ and the negative effects of depression and emotional distress on health-related quality of life and illness morbidity. ${ }^{31,32}$ In addition, many patients report that "getting right with God" is a significant priority for them as they face their own demise. ${ }^{9}$ As Fricchione $^{15}$ has suggested, the transition from wellness to illness or from illness to death is an inherently spiritual one because of questions regarding life meaning/purpose and separation anxieties that illness and impending death create. Therefore, medical care that recognizes and supports the spiritual nature of human beings is promoting the spiritual well-being that many patients are seeking at end of life. The LTI-SAGE is one avenue for encouraging this wellness, in part by reducing emotional distress without promoting a specific approach to religion or spirituality.

Clearly, however, the present study was limited by small sample size, which reduced the power of the statistical analyses. Further, the intent-to-treat analysis yielded only one significant outcome (death meaninglessness), even with the liberal statistical criterion of 0.10 , although the effect for depression was encouraging. The removal of seven noncompliant patients had little effect on the death meaninglessness result (other than strengthening the result a bit), but it did improve the outcomes for depression and religious spiritual well-being (without any impact on the other outcomes variable). With these considerations in mind, we believe the data support the efficacy of the LTI-SAGE when a sufficient "dose" of the treatment is given (i.e., if the patient attends most of the groups), particularly for spiritual well-being. The effect sizes for depression, spiritual wellbeing, and death meaninglessness were around the $10 \%$ level, which, for a psychosocial intervention where the outcomes are affected by a multitude of variables, approaches clinical relevance. In absolute terms, however, the effect sizes found here would be considered small. Equally clearly, the intervention had little effect on anxiety-like symptoms, including state anxiety and death-related fears, which is consistent with the literature on spiritual coping, which has shown a more consistent association between religion/ spirituality and the presence of depression than with anxiety disorders. ${ }^{33}$ The small sample size also reduced the interpretability of the results by not allowing a partitioning of effects as a function of diagnosis, race, or gender. It is conceivable that the effects reported here are primarily functions of one particular diagnostic group (e.g., cancer), race, or gender. Moreover, given that different facilitators worked with different diagnostic/race groups, the effects may have been inordinately influenced by a single facilitator who, despite the standardization of the group process, differed from other facilitators regarding communication skills, style, or other unknown factors. Future research with larger samples is clearly needed to investigate these possibilities. A final limitation of the study was that it could not be blinded. Both investigators, facilitators, and patients knew the group assignments and diagnoses. Although the randomly constituted control group preserved the internal validity of the study despite the lack of blinding, it is unclear to what extent knowledge of the intervention contributed to the size of the effect found. For example, patients in the intervention group may have been motivated to report improved well-being, particularly after having devoted 12 months to participation in the study and developing positive relationships with the group facilitators. Furthermore, the contribution of the positive expectations of the group facilitators to the reported differences cannot be separated from the contribution of the intervention.

The marginal findings suggested to us that the intervention could be made more intensive with the hopes that this would increase its impact. For example, posttrial debriefing sessions with patients and facilitators suggested that a once per month meeting schedule was too infrequent. Moreover, some of the sessions were considered less critical than others, including those related to more functional issues like healthcare planning. Shortening the length of the intervention from 12 months to 6 or 8 months was also suggested, but with more frequent meetings. Perhaps the most difficult aspect of the LTI-SAGE project was the health condition of the patients. Seriously ill patients have significant amounts of disability (which hampers the mobility and endurance needed to attend meetings), may not wish to travel to a central location for participation, often 
do not feel well, and also die during the course of participation. These factors make recruitment and retention difficult for trials of programs like LTI-SAGE. Compounding this patient-based phenomenon is the attitude of health professionals to psycho-socio-spiritual interventions. In our recruitment for this study, we encountered stiff resistance from individual physicians and clinics toward the distractions and disruptions that this type of intervention presumably entailed. ${ }^{17}$ There was also a prevalent perspective that intervening with seriously ill patients regarding the psychosocio-spiritual aspects of end of life would somehow cause the patient to give up, accept death, and/or refuse treatments. Without physician support for the intervention, it was difficult to recruit an adequate or representative sample. Thus, the participants may have differed in important ways from those who refused to participate, especially in illness severity and the desire to receive psycho-socio-spiritual care.

Despite the caveats attendant with this smallscale preliminary study, the LTI-SAGE appears to have promise for meeting some of the spiritual and emotional needs of seriously ill patients, especially with respect to depression, spiritual wellbeing, and death-related meaninglessness. Addressing the psycho-socio-spiritual aspects of the illness experience among those with life-threatening conditions may well enhance these patients' ability to meet their goal of living fully until death, rather than being typecast as "terminally ill." ${ }^{3}$ Clearly, patients with serious medical conditions frequently suffer psycho-socio-spiritual distress that is being inadequately addressed by modern health care. Additional research to improve the effectiveness of interventions to meet these needs is important and necessary. Results of the LTI-SAGE trial offer important insights into how to proceed.

\section{ACKNOWLEDGMENTS}

This study was supported by a grant from Supportive Care of the Dying: A Coalition for Compassionate Care, Portland, Oregon, and the Project on Death in America, New York, New York. The authors thank Dr. Mary Lou Bennett, Rev. Dr. Rosalind Denson, Rev. Wendell Reese, Rev. Edward Watson, Dr. Marc Shapiro, Dr. Sharon Frey, Fr. Patrick Norris, Rev. Ellen Hiatt, Dr. Gail Furman, Patrick Cacchione, and all the members of the study advisory committee for their invaluable assistance with this project.

\section{REFERENCES}

1. Kübler-Ross E: On Death and Dying. What the Dying Have to Teach Doctors, Nurses, Clergy and Their Own Families. New York: Macmillan, 1969.

2. Kübler-Ross E: Death: The Final Stage of Growth. Englewood Cliffs, NJ: Prentice-Hall, 1975.

3. McSkimming SA, Super A, Driever MJ, Schoessler M, Franey SG, Fonner E Jr: Living and Healing During LifeThreatening Illness. Portland, OR: Supportive Care of the Dying: A Coalition for Compassionate Care, 1997.

4. Prigerson HG, Jacobs SC: Perspectives on care at the close of life. Caring for bereaved patients: "All the doctors just suddenly go." JAMA 2001;286:1369-1376.

5. Lo B: Improving care near the end of life: Why is it so hard? JAMA 1995;274:1634-1636.

6. Quill TE: Initiating end-of-life discussions with seriously ill patients: Addressing the "elephant in the room." JAMA 2000;284:2502-2507.

7. The SUPPORT Principal Investigators for the SUPPORT Project: A controlled trial to improve care for seriously ill hospitalized patients: The Study to Understand Prognoses and Preferences for Outcomes and Risks of Treatments (SUPPORT). JAMA 1995;274: 1591-1598.

8. Lo B, Ruston D, Kates LW, Arnold RM, Cohen CB, Faber-Langendoen K, Pantilat SZ, Puchalski CM, Quill TR, Rabow MW, Schreiber S, Sulmasy DP, Tulsky JA: Discussing religious and spiritual issues at the end of life: A practical guide for physicians. JAMA 2002;287:749-754.

9. Steinhauser KE, Christakis NA, Clipp EC, McNeilly M, McIntyre L, Tulsky JA: Factors considered important at the end of life by patients, family, physicians, and other care providers. JAMA 2000;284:2476-2482.

10. Brody H, Campbell ML, Faber-Langendoen K, Ogle KS: Withdrawing intensive life-sustaining treatment-Recommendations for compassionate clinical management. N Engl J Med 1997;336:652-657.

11. Spiegel D, Spira J: Supportive-Expressive Group Therapy: A Treatment Manual of Psychosocial Intervention for Women with Recurrent Breast Cancer. Stanford, CA: Psychosocial Treatment Laboratory, Stanford University School of Medicine, 1991.

12. Fawzy FI, Fawzy NW, Arndt LA, Pasnau RO: Critical review of psychosocial interventions in cancer care. Arch Gen Psychiatry 1995;52:100-113.

13. Freedman $\mathrm{O}$, Orenstein $\mathrm{S}$, Boston $\mathrm{P}$, Amour T, Seely J, Mount BM: Spirituality, religion, and health: A critical appraisal of the Larson reports. Ann R Coll Physicians Surg Can 2002;35:90-93.

14. Ellison C: Spiritual well-being: Conceptualization and measurement. J Psychol Theol 1983;11:330-340.

15. Fricchione GL: Religious issues in the context of medical illness. In: Stoudemire A, Fogel BS, Greenberg D 
(eds): The Psychiatric Care of the Medical Patient, 2nd ed. New York: Oxford University Press, 2000, pp. 91-104.

16. Chibnall JT, Videen SD, Duckro PN, Miller DK: Psycho-social-spiritual correlates of death distress in patients with life-threatening medical conditions. Palliat Med 2002;16:331-338.

17. Miller DK, Chibnall JT: Recruiting patients into randomized trials of palliative care: Experience and suggestions. Palliat Med 2003;17:556-557.

18. Beck AT, Ward CH, Mendelson M, Mock J, Erbaugh $\mathrm{J}$ : An inventory for measuring depression. Arch Gen Psychiatry 1961;4:561-571.

19. Spielberger CD, Gorsuch RL, Lushene R: Manual for the State-Trait Anxiety Inventory. Palo Alto, CA: Consulting Psychologists Press, 1983.

20. Hill PD, Hood RW Jr: Measures of Religiosity. Birmingham, AL: Religious Education Press, 1999.

21. Triplett G, Cohen D, Reimer W, Rinaldi S, Hill C, Roshdieh S, Stanczak EM, Siscoe K, Templer DI: Death discomfort differential. Omega 1995;31:295-304.

22. Siscoe K, Reimer W, Yanovsky A, Thomas-Dobson S, Templer DI: Death depression versus death anxiety: Exploration of differential correlates. Psychol Rep 1992;71:1191-1194.

23. Chibnall JT, Tait RC: The Pain Disability Index: Factor structure and normative data. Arch Phys Med Rehabil 1994;75:1082-1086.

24. Procidano ME, Heller K: Measures of perceived social support from friends and family: Three validation studies. Am J Community Psychol 1983;11:1-24.

25. Brown A, Mistry T: Group work with "mixed membership" groups: Issues of race and gender. Soc Work Groups 1994;17:5-21.
26. Davis L, Cheng L, Strube M: Differential effects of racial composition on male and female groups: Implications for group work practice. Soc Work Res 1996;20:157-166.

27. Miller DK, Duckro/Videen SD, Chibnall JT: /The LTISAGE/Program. 〈www.careofdying.org/Resources/〉 LifeThreateningServicesAndTrainingProgramOperationsManual.pdf $\rangle$ (Last accessed March 28, 2005).

28. Jaccard J, Becker MA: Statistics for the Behavioral Sciences, 2nd ed. Belmont, CA: Wadsworth, 1990.

29. Newlin K, Melkus GD, Chyun D, Jefferson V: The relationship of spirituality and health outcomes in Black women with type 2 diabetes. Ethnic Dis 2003;13:61-68.

30. McClain CS, Rosenfeld B, Breitbart W: Effect of spiritual well-being on end-of-life despair in terminallyill cancer patients. Lancet 2003;361:1603-1607.

31. King KB: Psychologic and social aspects of cardiovascular disease. Ann Behav Med 1997;19:264-270.

32. Rigler SK: Managing poststroke depression in older people. Clin Geriatr Med 1999;15:765-783.

33. Larson DB, Swyers JP, McCullough ME (eds): Scientific Research on Spirituality and Health: A Consensus Report. Rockville, MD: National Institute for Healthcare Research, 1998.

Address reprint requests to: Douglas K. Miller, M.D. Indiana University Center for Aging Research Indiana University School of Medicine 1050 Wishard Boulevard, RG-6 Indianapolis, IN 46202

E-mail: dokmille@iupui.edu 